\title{
基于多米诺反应合成吲哚衍生物
}

\author{
冯亚栋张红程国林* 崔秀灵* \\ (分子药物教育部工程研究中心 厦门市海洋与基因工程药物重点实验室 \\ 华侨大学分子药物学研究所 厦门 361021)
}

\begin{abstract}
摘要 近年来, 多米诺反应作为合成吲哚衍生物的有效方法已得到有机合成化学家的广泛关注. 该反应过程中, 不需 改变反应条件和添加试剂，中间体也无需分离和提纯，实现了原子经济和环境友好的目标. 通过过渡金属催化的多米 诺反应合成吲哚衍生物, 已经得到了深入研究并成为一种构筑该类杂环的有利工具. 重点综述了近年来运用金属催化 多米诺反应合成啊哚及其衍生物方面的研究进展, 以催化剂的类型进行分类, 介绍相关反应的特点和优势.

关键词 多米诺反应; 金属催化; 吲哚衍生物; 合成
\end{abstract}

\section{Synthesis of Indole Derivatives via Domino Reactions}

\author{
Feng, Yadong Zhang, Hong Cheng, Guolin* Cui, Xiuling* \\ (Engineering Research Center of Molecular Medicine, Ministry of Education, Xiamen Key Laboratory of Marine and \\ Gene Drugs, Institutes of Molecular Medicine, Huaqiao University, Xiamen 361021)
}

\begin{abstract}
Domino reactions have received great attentions of organic chemist as an efficient protocol to synthesize indole derivatives. In this process, it is not required isolating or purifying the intermediates, changing the reaction condition and adding reagents. Transition metal-catalyzed domino reactions to synthesize indole derivatives have already been widely studied and become a powerful tool. In this paper, the progress of recent domino reactions applied to construct indole and its derivatives is reviewed, focusing on the transition metal-catalyzed domino reactions, and detailed analysis on the versatility and applications.
\end{abstract}

Keywords domino reactions; metal catalysis; indole derivatives; synthesis

吲哚普遍存在于天然产物和药物分子中 ${ }^{[1,2]}$. 由于 它与许多受体之间存在较强的亲和力 ${ }^{[3]}$, 被认为是 “优 势结构” . 对吲哚合成方法的探索一直以来是化学工作 者致力于研究的课题, 现已经研究出许多有效的方法, 比如传统的 Fischer 合成法 ${ }^{[4]}$ 、Mori 合成法 ${ }^{[5]}$ 、 Hemetsberger 合成法 ${ }^{[6]}$ 、Buchwald 合成法 ${ }^{[7]}$ 、Sundberg 合成法 ${ }^{[8]} 、$ Nenitzescu 合成法 ${ }^{[9]} 、$ Larock 合成法 ${ }^{[10]}$ 等. 这 些反应大都存在反应底物复杂、操作步骤繁多、底物适 用范围窄、产率较低和选择性差等缺点, 因此, 近年来 化学家致力于探索合成吲哚的新途径, 希望能够找到操 作简便、效率高和选择性好的新方法. 近年来, 国内许 多优秀的课题组在该领域中对经典方法的发展 ${ }^{[11]}$ 和新 方法的探索方面都取得了突破性的进展. 例如, 马大为 课题组 ${ }^{[12]}$ 通过发展高效的 $\mathrm{LiHMDS} / \mathrm{I}_{2}$ 反应体系, 实现
了 4 种复杂吲哚生物碱的全合成, 并证明了氧化偶联反 应是一种高效经济的 $\mathrm{C}-\mathrm{C}$ 键构建策略 ${ }^{[13]}$. 胡文浩课题 组 ${ }^{[14]}$ 通过对映选择性质子化快速高效地实现了吲哚的 不对称 $\mathrm{C}-\mathrm{H}$ 官能团化反应.

多米诺反应(domino reaction) 是指在特定反应条件 下，巧妙地使两个或两个以上化学键一锅连续形成，以 构筑各种碳-碳键、碳一杂键. 在整个反应过程中不需添 加试剂或催化剂, 前一步形成的中间体与下一步形成的 中间体共用一个过渡态 ${ }^{[15,16]}$. 通过巧妙设计, 多米诺反 应能够很大程度地提高反应产率和原子利用率. 近年 来, 从经济节约、环境友好、操作简便和原子经济性 ${ }^{[17]}$ 等角度出发, 多米诺反应在有机合成中的应用越来越广 泛. 很多化学工作者已经把注意力放在了利用此类反应 来构筑吲哚及其衍生物上，并且报道了许多巧妙的合成

\footnotetext{
*E-mail: glcheng@hqu.edu.cn; cuixl@hqu.edu.cn

Received March 6, 2014; revised May 4, 2014; published online May 23, 2014.

Project supported by the Minjiang Scholar Program (No. 10BS216), the Xiamen Southern Oceanographic Center (No. 13GYY003NF16), and the Fundamental Research Funds of Huaqiao University.

福建省闽江学者计划(No. 10BS216)、厦门南方海洋研究中心(No.13GYY003NF16)、华侨大学基本科研业务基金资助项目.
} 
方法. 2002 年, Cacchi 课题组 ${ }^{[18]}$ 已经对利用钯催化的还 原消除多米诺反应来构建官能化吲哚环的反应进行了 详细的综述, 所以本文对其之后的多米诺反应在颉哚合 成方面的研究进展进行综述, 以各种不同金属催化的多 米诺反应为重点和催化剂种类的不同为依据进行分类, 通过对相关反应的特点、反应条件、反应收率及适用范 围的比较, 简要提出该领域今后发展的重点和趋势.

\section{1 过渡金属催化的多米诺吲哚合成}

\section{1 钯催化的多米诺吲哚合成方法}

近几年来, 基于钯催化的多米诺反应合成复杂天然 产物或药物母核的报道屡见不鲜. 2007 年, Barluenga 课 题组 ${ }^{[19]}$ 报道了以氮杂烯丙基阴离子作为合成子的多米 诺合成吲哚的反应, 他们利用邻二溴苯和乙酰苯亚胺为 原料，巧妙地通过连续的 $\alpha$-芳基化反应和分子内氨基化 反应一步合成了吲哚衍生物(Scheme 1). 在反应过程中, 化合物 1 首先经过 $\alpha$-芳基化反应，与化合物 2 作用生成 亚胺化合物 3, 它的互变异构体烯胺化合物 4 再经过分 子内氨基化反应, 直接生成吲哚衍生物 $\mathbf{5}$. 该反应新颖 高效, 区域选择性和底物适用性较好, 各种邻二卤代苯 衍生物以及邻卤代磺酸盐类化合物都可以发生该反应， 并且可以将卤化烯烃与胺生成亚胺的反应与之结合, 形 成三组分多米诺吲哚合成反应 ${ }^{[20]}$.

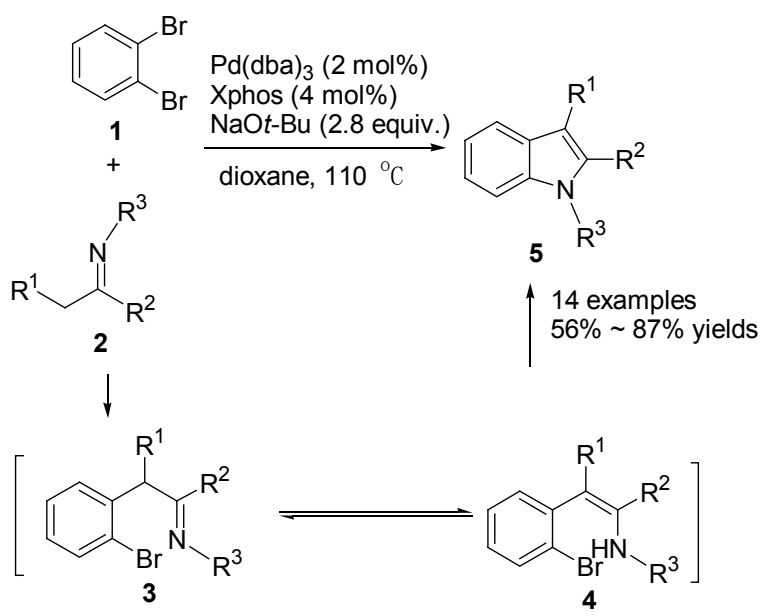

Scheme 1

2007 年, Jørgensen 课题组 ${ }^{[21]}$ 报道了钯催化芳基氨 基化-Heck 环化串联过程, 巧妙地一步生成 3-取代吲哚 的反应(Scheme 2). 在反应过程中, 邻碘溴代芳烃 6 首 先与化合物 $\mathbf{7}$ 进行氨基芳基化反应生成 $\mathbf{8}$, 化合物 $\mathbf{8}$ 再进行分子内 Heck 环化反应直接生成 3-取代吲哚化合 物. 该反应条件温和, 构思巧妙, 为一步合成 3-取代吲 哚化合物提供了一种具有参考价值的方法.

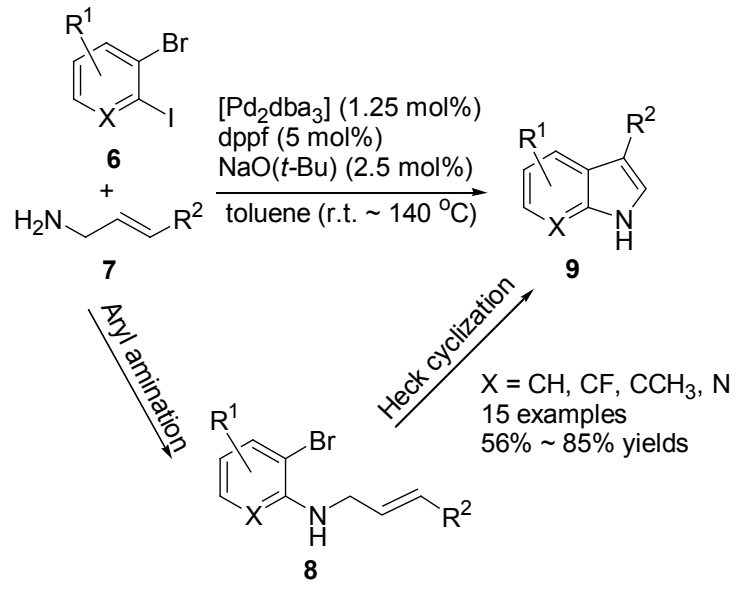

Scheme 2

2008 年, Glorius 课题组 ${ }^{[22]}$ 提出了一种钯催化 $N$-芳 基烯胺氧化环化反应，一步合成多取代吲哚衍生物的反 应(Scheme 3). 反应过程中, 化合物 10 首先与钯催化剂 反应生成钯化物 11, 对照试验以及动力学同位素效应 试验表明，该化合物接下来发生 $\sigma$-键置换反应，生成中 间体 12, 或者通过碱促进的脱质子化反应, 生成中间体 13，随后进行还原消除反应生成吲哚衍生物 5 . $\mathrm{Cu}(\mathrm{OAc})_{2}$ 为氧化剂, 完成催化循环的作用.

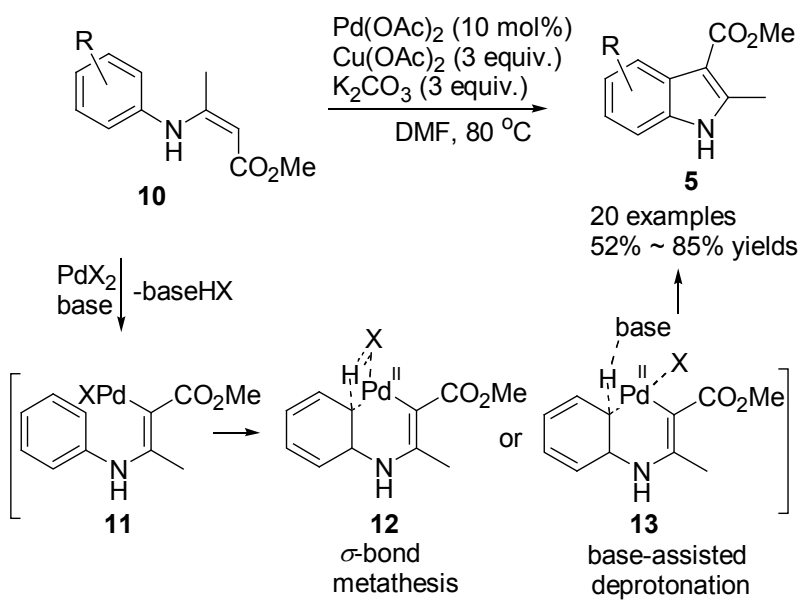

Scheme 3

2009 年, 焦宁课题组 ${ }^{[23]}$ 发表一篇由简单苯胺和炔 烃, 经过钯催化 $\mathrm{C}-\mathrm{H}$ 活化一步生成吲哚衍生物的反应 (Scheme 4). 该反应中, 钯催化剂可以作为 Lewis 酸活化 炔烃 15, 发生氢胺化反应, 生成的烯胺随后于 Pd 发生 亲电取代反应生成中间体 $\mathbf{1 6}$, 或者炔烃发生胺钯化反 应生成中间体 16, 随后进攻芳烃生成中间体 17, 最后发 生还原消除生成吲哚化合物 5. 该反应不仅适用于 $\mathrm{N}$ 位 无取代的苯胺，也适用于 $\mathrm{N}$ 位烷基单取代的苯胺，反应 条件温和, 无需加入配体和碱, 分子氧为氧化剂, 是一 种简便、新颖、高效的吲哚合成方法. 


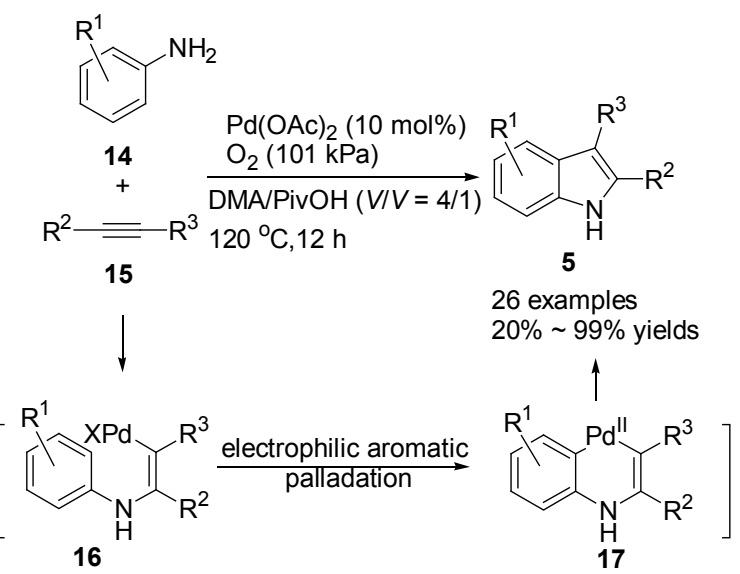

Scheme 4

2-芳酰基吲哚具有抗细胞增殖和抑制微管蛋白聚 合的活性 ${ }^{[24,25]}$, Florent 小组 ${ }^{[26]}$ 于 2009 年提出了一种合成 该类化合物的多米诺反应. 他们以 2-偕-二溴乙烯基苯 胺 18 与嗍酸 19 为底物, 在 $\mathrm{CO}$ 氛围中, 钯催化一锅合 成了 2-芳酰基/杂芳酰基吲哚衍生物 20 (Eq. 1). 在优化 条件下，该反应能够适用于多种取代基的 2-芳酰基/杂 芳酰基吲哚的合成, 产率可达 73\%, 为进一步合成具有 生物活性的复杂化合物提供了一种经济实用的方法.

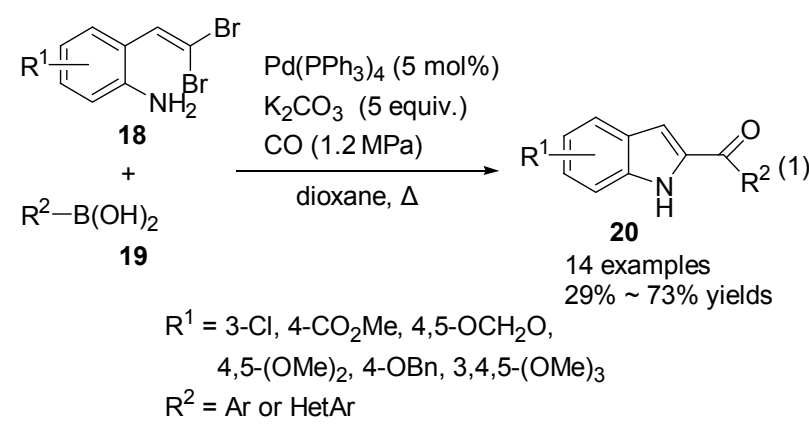

2010 年, Sun 小组 ${ }^{[27]}$ 以邻碘 $-N$-烯丙基亚胺为底物, 利用钯催化分子内 Heck 偶联与脱烷基化作用, 成功地 合成了 2-取代吲哚化合物(Scheme 5). 在该反应过程中,

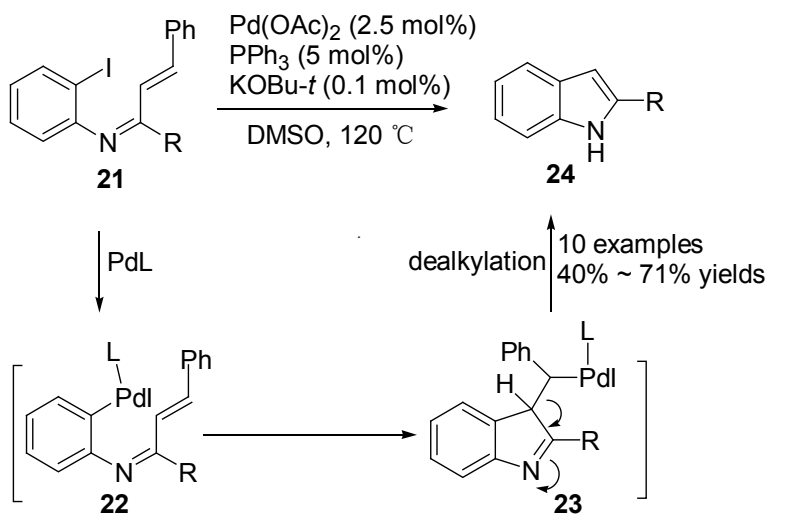

Scheme 5
化合物 21 经氧化加成形成中间体 22 , 随后进行分子内 Heck 反应形成中间体 23, 最后进行脱烷基化作用同时 芳构化合成吲哚产物 24, 产率可达 71\%. 研究证明, 反 应最后不是 $\beta$-氢消除而是脱烷基化反应, 这与传统的 Heck 反应机理 ${ }^{[28]}$ 有所不同, 为设计钯催化的新型反应 提供了有价值的参考.

另外，利用降冰片烯参与钯催化的碘代芳烃、碘代 烷烃和烯烃的三组分多米诺反应，称为 Catellani 反 应 ${ }^{[29]}$. 该反应能够利用简单易得的原料同时构筑 3 个 C- $\mathrm{C}$ 键, 在有机合成上具有深远的意义. 2010 年

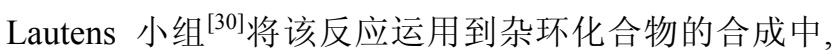
报道了一个有趣的多米诺反应. 他们利用降冰片烯来调 节钯催化的 $2 H$-呋丙因和芳基碘化物的反应，生成吗哚, 产率 54\% 95\% (Scheme 6).

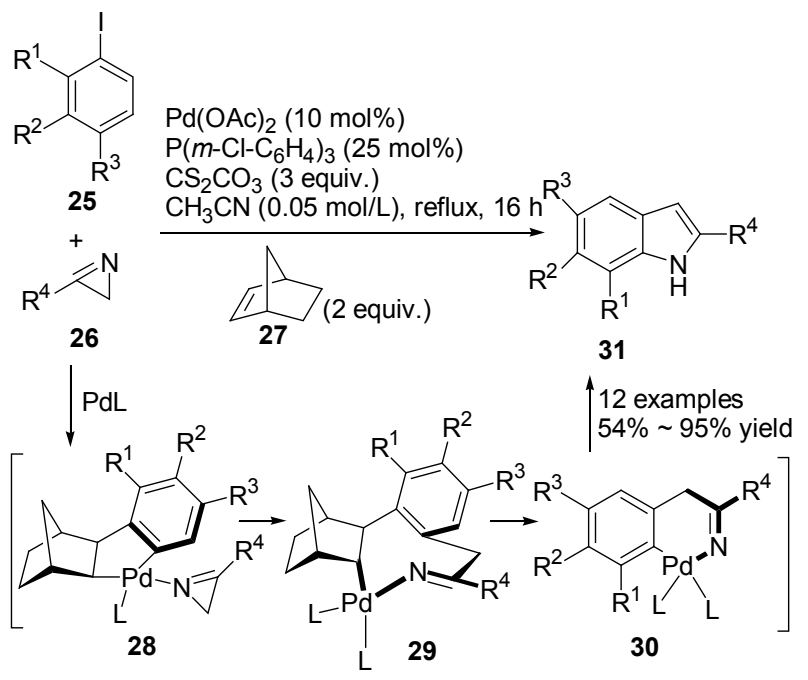

$\mathrm{R}^{1}=\mathrm{Me}, \mathrm{MeO}, \mathrm{Cl} ; \mathrm{R}^{2}=\mathrm{H}, \mathrm{F}, \mathrm{CF}_{3} ; \mathrm{R}^{3}=\mathrm{H}, \mathrm{NHAc} ; \mathrm{R}^{4}=\mathrm{Ar}$

\section{Scheme 6}

该反应与降冰片烯介导的 $\mathrm{C}-\mathrm{H}$ 键活化官能化反应 有着类似的催化循环机理 ${ }^{[31]}$. 降冰片烯 27 先和催化剂 形成碳钯化合物, 然后与芳基卤代物 $\mathbf{2 5}$ 进行氧化加成、 亲电子的金属化作用以及去质子化作用生成环钯中间 体, $2 H$-呋丙因 26 易与 $\mathrm{Pd}(\mathrm{II})$ 配位 $^{[32]}$ 生成中间体 28, 再一 次氧化加成并导致 $\mathrm{C}-\mathrm{N}$ 单键断裂开环, 然后选择性地 生成中间体 29, 通过脱碳钯化作用生成中间体 $\mathbf{3 0}$, 最 后通过还原消除反应和互变异构生成吲哚产物 31. 这 是首次利用芳基钯中间体和 $2 \mathrm{H}$-听丙因来合成颉哚的方 法, 并且是利用两个小分子的应变能引发的化合物的转 化，丰富了传统的合成方法.

近年来, 通过钯催化 $\mathrm{C}-\mathrm{H}$ 键活化来直接构建碳碳键和碳一杂原子键也是有机化学研究的一个热点, 此 类反应大大拓展了传统偶联反应的底物范围, 已经成为 多米诺反应中的一个有效的步骤 ${ }^{[33,34]}$. Takemoto 小组 ${ }^{[35]}$ 
在 2012 年首次报道了钯催化的, 由异腈的插入和苠基 $\mathrm{C}\left(\mathrm{sp}^{3}\right)-\mathrm{H}$ 键活化组成的多米诺反应, 成功地合成了吲 哚(Scheme 7).

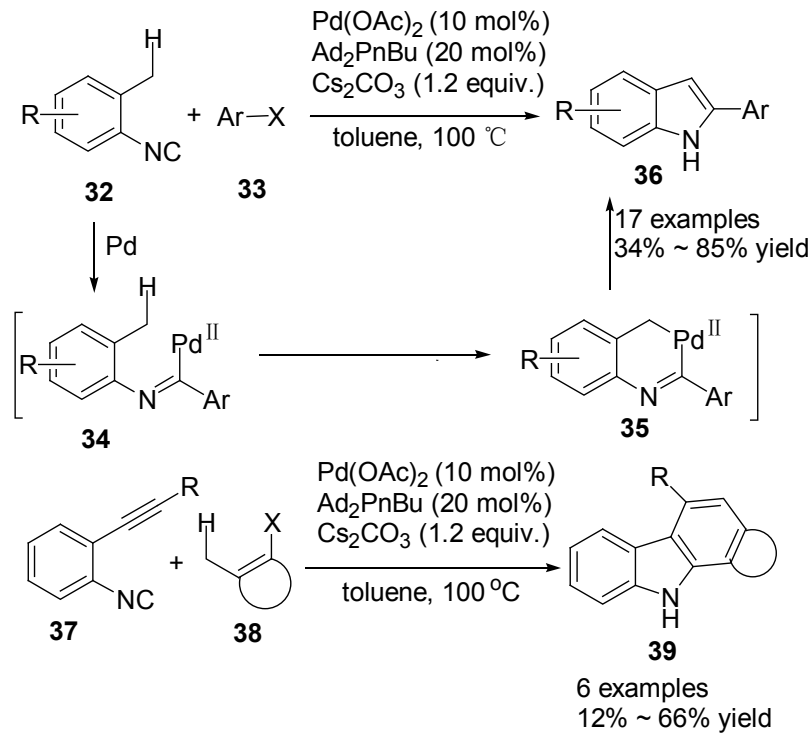

Scheme 7

该反应由芳基卤化物 33 与钯催化剂的氧化加成启 动, 经过异腈衍生物 32 的插入反应形成中间体 34, 继 而由 $\mathrm{C}\left(\mathrm{sp}^{3}\right)-\mathrm{H}$ 键活化形成环钯化物 35 , 最后还原消除 生成产物 36, 产率可达 $85 \%$. 缓慢地加入异腈能够有效 地减少催化剂的用量. 另外, 利用该方法, 以炔烃 37 和 卤化物 38 为底物, 可用于合成四环咔唑衍生物 39, 产 率能达到 $66 \%$. 该反应在形成两个或者 3 个 $\mathrm{C}-\mathrm{C}$ 键的 过程中能够避免钯催化剂的失活, 简单高效, 已被拓展 到用于合成各类含氮多环化合物, 例如苯并咔唑、吲哚 并咔唑以及含有硝基的多环化合物.

2013 年, $\mathrm{Zhu}$ 小组 ${ }^{[36]}$ 报道了一种同样利用 $\mathrm{C}-\mathrm{H}$ 键 活化, 在氧气条件下, 由 $N$-炔基苯胺, 一步合成三环吲 哚衍生物的多米诺反应，产率最高达到 $83 \%$ (Scheme 8). 反应始于化合物 40 与 $\mathrm{Pd}(\mathrm{II})$ 配位, 通过中间体 41 实现
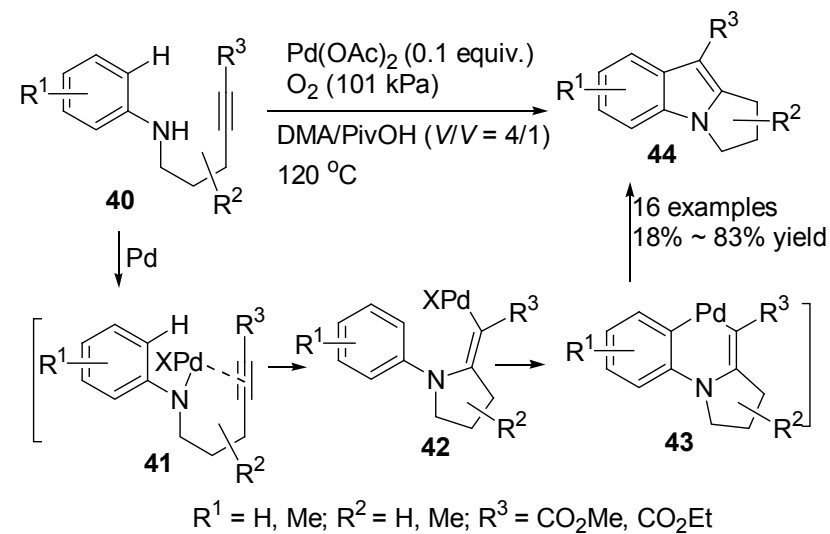

Scheme 8
炔基的顺式胺钯化作用，并生成烯基中间体 42. 随后邻 位芳环上 $\mathrm{C}-\mathrm{H}$ 键的活化生成六元环钯中间体 $\mathbf{4 3}$, 最后 发生还原消除反应生成吡咯并 $[1,2-a]$ 吲哚衍生物 44. 氧 气的作用是在催化循环中将 $\mathrm{Pd}$ 氧化, 重新得到活性催 化剂物种. 该方法能够简单高效地构建吡咯并吲哚三环 结构. 此类多环化合物是许多重要的具有生物活性的天 然产物和药物的结构基元 ${ }^{[37]}$.

3-烯基取代的吲哚因其易修饰而广泛地应用于吲 哚生物碱 ${ }^{[38]}$ 、咔唑 ${ }^{[39]}$ 和咔啉 ${ }^{[40]}$ 的合成中. 对其合成方法 的研究一直以来都被许多课题组所关注. 2013 年 $\mathrm{Yu}$ 小 组 ${ }^{[41]}$ 报道了钯催化合成 3-烯基吲哚的多米诺反应(Eq. 2). 利用 2-叠氮基-3-芳基丙烯酸酯(45)和末端烯烃 46 在 催化量的醋酸钯催化下, 以氧气为氧化剂, 经过配位、 重排、 $\mathrm{C}-\mathrm{H}$ 键活化、烯烃插入和 $\beta$-氢消除的过程, 在 室温条件下生成了 3-烯基吲哚 47, 产率最高可达 $83 \%$. 缺电子的烯烃, 包括丙烯酸酯和丙烯腈, 能与 2-叠氮-3苯基丙烯酸乙酯反应，区域选择性地生成对应的 3-烯基 吲哚. 其他的烯烃, 如 $N$-乙基丙烯酰胺、苯乙烯和 3-甲 基丁-1-烯等，反应活性则较低. 该方法虽然条件温和、 操作简便、原料易得, 但是适用范围不广.
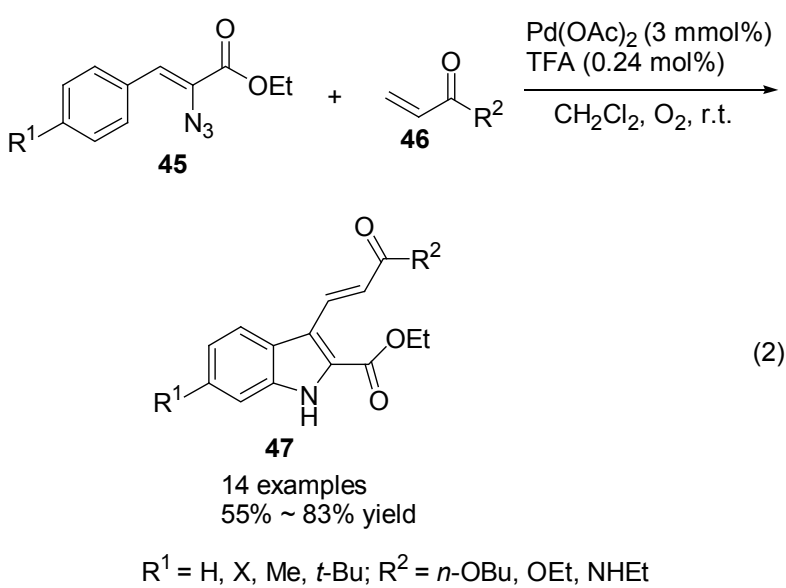

Pullarkat 小组 ${ }^{[42]}$ 于 2012 以邻一炔基苯胺 49 为底物, 在环钯化合物 48 催化下发生环化反应生成吲哚中间体, 随后与烯丙醇 50 进行烷基化作用，生成 2,3-二取代吲哚 化合物 51 或 52，产率高达 98\% (Eq. 3). 该反应中，当 $\mathrm{R}^{3}=4-\mathrm{MeC}_{6} \mathrm{H}_{4}$ 时，反应缺乏区域选择性，实验结果表明 该反应过程中产生的吲哚中间体的烷基化步骤是按着 Tsuji-Trost 方式 ${ }^{[43]}$ 进行, 而不是常见的 Friedel-Crafts 方 式 ${ }^{[44]}$. 此外, 该反应以醇类作为烷基化试剂, 具有较高 的创新性和实用性.

\section{2 铜催化的多米诺吲哚合成}

以芳基卤化物与合适的试剂进行的 Ullmann 偶联反 应 $^{[45]}$ 已经被大量的报道. 鉴于铜更经济廉价，此类催化 


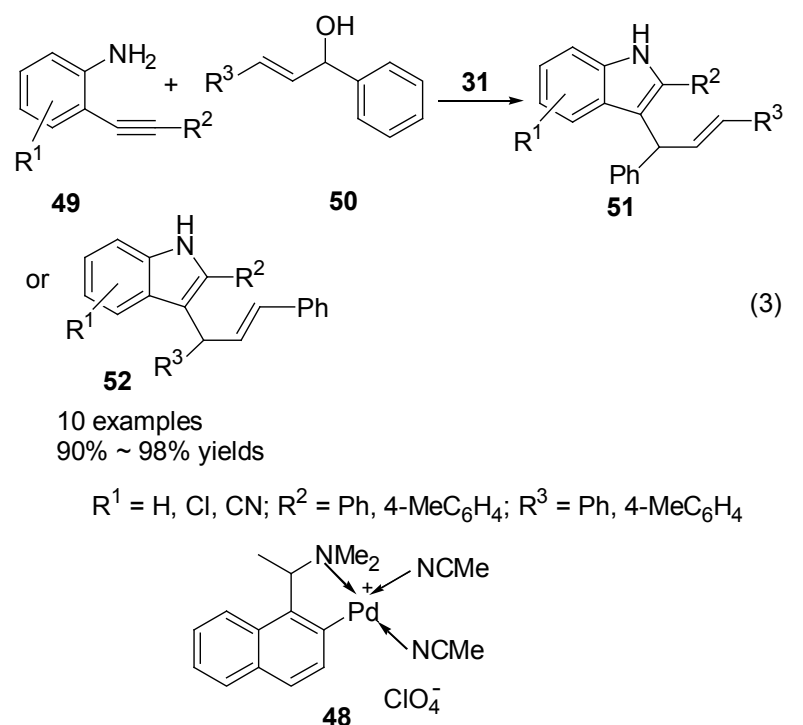

剂也受到更广泛的关注 ${ }^{[46,47]} .2007$ 年, 马大为课题组 ${ }^{[48]}$ 报道了一种铜催化芳基化一缩合串联反应来合成多取代 吲哚的反应(Scheme 9). 反应过程中, 在邻位基团的影 响下, 2 -碘代三氟乙酸苯胺 $(\mathbf{5 3})$ 与 $\beta$-酮酸酯 54 反应生成 酰胺 55, 然后在酸性条件下水解生成苯胺 56, 随后胺基 进攻酮羰基生成 2,3-双取代吲哚衍生物 57. 该反应巧妙 地将 2 -卤代三氟乙酸苯胺与 $\beta$-酮酸酯的偶联反应和酰 胺酸性水解反应串联起来, 简便高效地合成双取代吲 哚，底物适用性非常广泛.
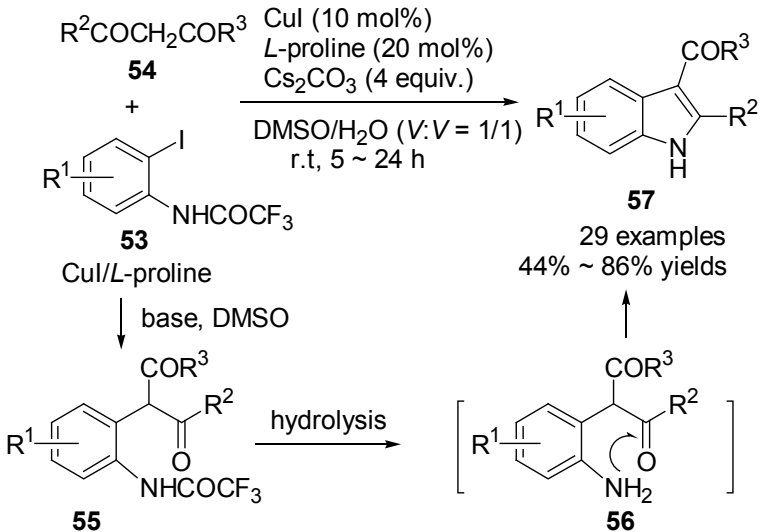

Scheme 9

Punniyamurthy 等 ${ }^{[49]}$ 在 2010 年报道了一种氧化亚铜 催化合成多取代吲哚的多米诺反应. 他们以 2-卤代苯胺 58 与 1,3-二羰基化合物 59 为底物, 在氮气氛中反应得 到吲哚产物, 产率为 $62 \% \sim 91 \%$ (Scheme 10). 该反应开 始于化合物 58 与化合物 59 的缩合反应，形成亚胺中间 体 60, 继而与 $\mathrm{Cu}(\mathrm{I})$ 氧化加成形成 $\mathrm{Cu}(\mathrm{III})$ 中间体 61, 随 后与碱作用生成中间体 62 , 再通过亲核取代转化成中 间体 63, 并释放出卤化物, 最后发生还原消除生成吲哚 产物 64. 该方法包含分子间缩合反应与分子内 $\mathrm{C}-\mathrm{C}$ 交
叉偶联反应的连续过程. 反应条件温和、原料经济易得、 不需配体，具有良好的原子经济性. 另外，底物适用范 围广泛，包括卤素、烷基、芳基、硝基和双取代基等. 该 反应没有副产物产生，具有很好的选择性，广泛地应用 于区域选择性地合成多取代吲哚衍生物.

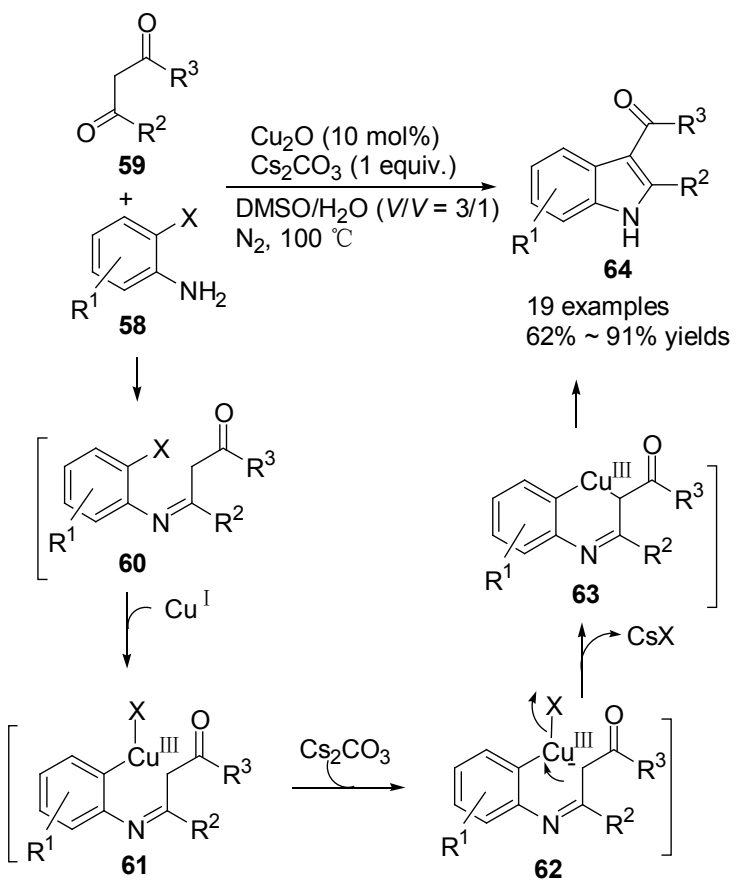

$\mathrm{X}=\mathrm{Br}, \mathrm{l} ; \mathrm{R}^{1}=\mathrm{H}, \mathrm{Cl}, \mathrm{Me}, \mathrm{NO}_{2} ; \mathrm{R}^{2}=$ alkyl, aryl; $\mathrm{R}^{3}=$ alkyl, alkoxy, NHAr

\section{Scheme 10}

$\mathrm{Lv}$ 小组 ${ }^{[50]}$ 在 2011 年首次发现了一种 $\mathrm{Cu}_{2} \mathrm{O}$ 催化的 分子内 $\mathrm{C}-\mathrm{N}$ 偶联 $/ \mathrm{C}-\mathrm{Y}(\mathrm{Y}=\mathrm{O}, \mathrm{S})$ 键形成的多米诺反 应，并以此来简单高效地合成多环的哚衍生物. 他们 利用邻偕二溴乙烯基水杨酰苯胺 65 为反应底物，在 $\mathrm{Cu}_{2} \mathrm{O}$ 催化条件下生成多环吲哚衍生物, 产率可高达 96\% (Scheme 11). 他们非常巧妙地利用了邻-偕二溴乙 烯基化合物 65 作为 $N, Y$-双齿配体的特性 ${ }^{[51]}$ ，与低价态 的 $\mathrm{Cu}$ 螯合后发生氧化加成，并在碱作用下生成环状中 间体 66, 随后形成 $\mathrm{C}-\mathrm{N}$ 键而生成新增单环的中间体 67. 然后在此基础上, 通过中间体 68 和 69 再次形成 $\mathrm{C}-\mathrm{Y}$ 键，生成新增双环的产物 70. 该反应提供了一种 快速、温和地合成多杂环吲哚衍生物的方法，包括复杂 的噻唑[3,2- $a$ 吲哚-12-酮和吲哚 [2,1- $b$ ]喹唑啉-12-酤等 化合物，也适用于大规模地生产多环化合物. 另外，此 类方法为合成高价值的咪唑并吲哚䣶类化合物提供了 一种有效方法.

2011 年, Miura 等 ${ }^{[52]}$ 报道了一种由醋酸铜催化的邻炔基苯胺 71 和唑类 72 发生 $\mathrm{C}-\mathrm{H} / \mathrm{N}-\mathrm{H}$ 偶联/环化的多 米诺反应，生成相应的 $N$-唑基吲哚衍生物，产率最高可 达 90\% (Scheme 12). 反应过程中，反应底物 71 和 72 在 
<smiles>[R][R]1cccc(C([R3])=C(Br)Br)c1NC(=O)c1ccccc1Br</smiles>

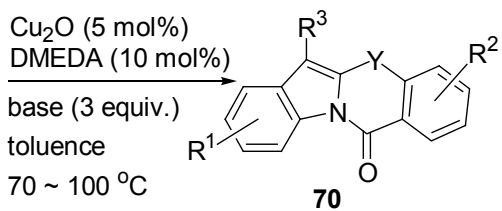

65

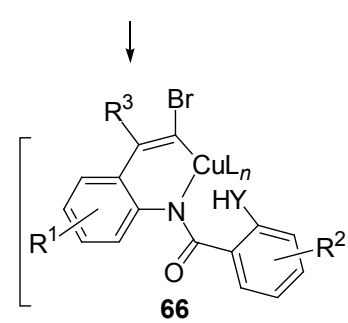<smiles>CCCCCC(C)CC</smiles><smiles>[R]c1ccc(C(=O)n2c(Br)c([R])c3ccc([R])cc32)c([R])c1</smiles>

67
15 examples $76 \% \sim 96 \%$ yield<smiles>[R]c1ccc(C(=O)n2c(Cl)c([R3])c3ccccc32)c([Y])c1</smiles>

69

Base $\cdot \mathrm{HBr}$

副产物是易除去的 $\mathrm{CO}_{2}{ }^{[54]}$ ，此类反应已被证实是一种有 效的构建 $\mathrm{C}-\mathrm{C}$ 键的方法. 尽管钯催化的此类反应的例 子已经报道了很多，但是单独用铜催化的脱羧偶联反应 却很少. 2012 年, Muthusubramanian 小组 ${ }^{[55]}$ 报道了通过 溴化铜催化脱羧偶联反应合成 2-芳基吲哚的多米诺方 法(Eq. 4). 该反应以丙炔基羧酸 76 和芳基碘化物 75 为 原料，经过脱羰基交叉偶联/环化反应的连续多米诺过 程生成产物 77, 产率高达 90\%。 与传统方法相比，该方 法简便高效、原料易得、取代基范围较宽，有利于进一 步的合成转化.

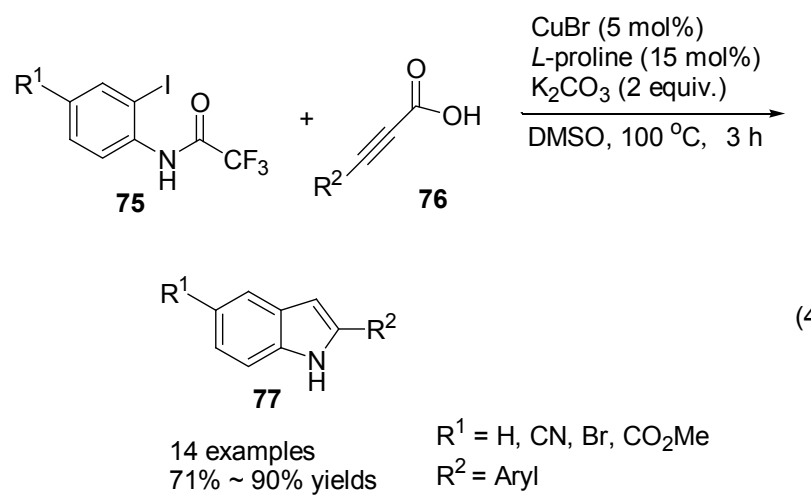

\section{3 金催化的多米诺吲哚合成}

早在 2007 年, Marinelli 等 ${ }^{[56]}$ 报道了一种利用 $[\mathrm{bmim}] \mathrm{BF}_{4}$ 作溶剂，金催化的、邻炔基苯胺(78)和 3-丁 烯-2-酮(79)为底物的 aza-Michael 加成/环化/烷基化的多 米诺过程，经过中间体 $\mathbf{8 0}$, 一步生成三取代吲哚 81 的 方法(Scheme 13)。该反应表明，在 $[\mathrm{bmim}] \mathrm{BF}_{4}$ 中，金盐 能有效地催化 2-炔基苯胺发生环化反应生成多取代吲 哚. 另外，使用微波加热能明显缩短反应时间. 该反应 产率虽然不高，只有 $40 \%$ ，但是开辟了一种金催化的， 以简单原料 “一锅煮” 合成三取代吲哚的新途径.

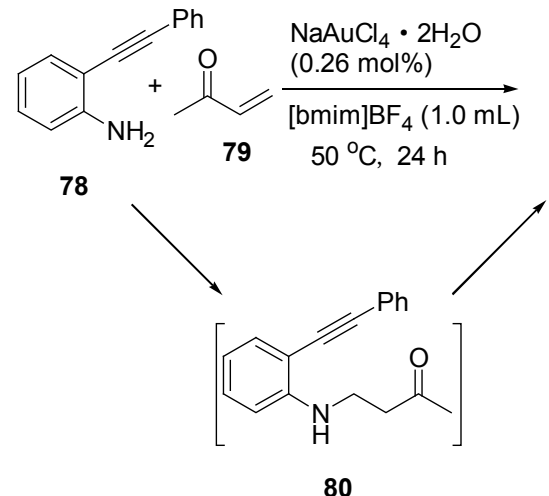

Scheme 13

\section{Scheme 12}

此外，羧基作为有效的离去基团参与的偶联反应，

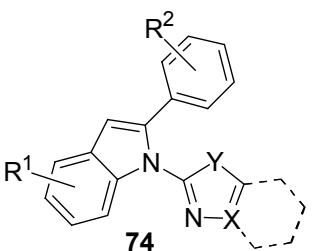

$\mathrm{X}=\mathrm{CH}, \mathrm{N}$

$\mathrm{Y}=\mathrm{O}, \mathrm{S}$ $69 \% \sim 90 \%$ yields 
以邻炔基苯胺 82 为底物, 以 $\mathrm{AuCl}$ 为催化剂, 合成一系 列吲哚衍生物的多米诺反应(Scheme 14). 反应中底物 82 与醛类 83 反应经过中间体 84 生成二吲哚基甲烷衍生 物 85 . 化合物 82 与靛红 86 在相同条件下反应能生成二 吲哚基吲哚啉-2-酮(87). 另外, 化合物 82 还能与硝基烯 烃 88 在相同的条件下反应生成 2-吲哚基-1-硝基烷烃 (89). 该方法能够简单有效地合成双吲哚基甲烷类、双 吲哚基吲哚啉-2-酮类和 2-吲哚基-1-硝基烷类化合物, 它们都是非常重要的具有药物活性的分子.
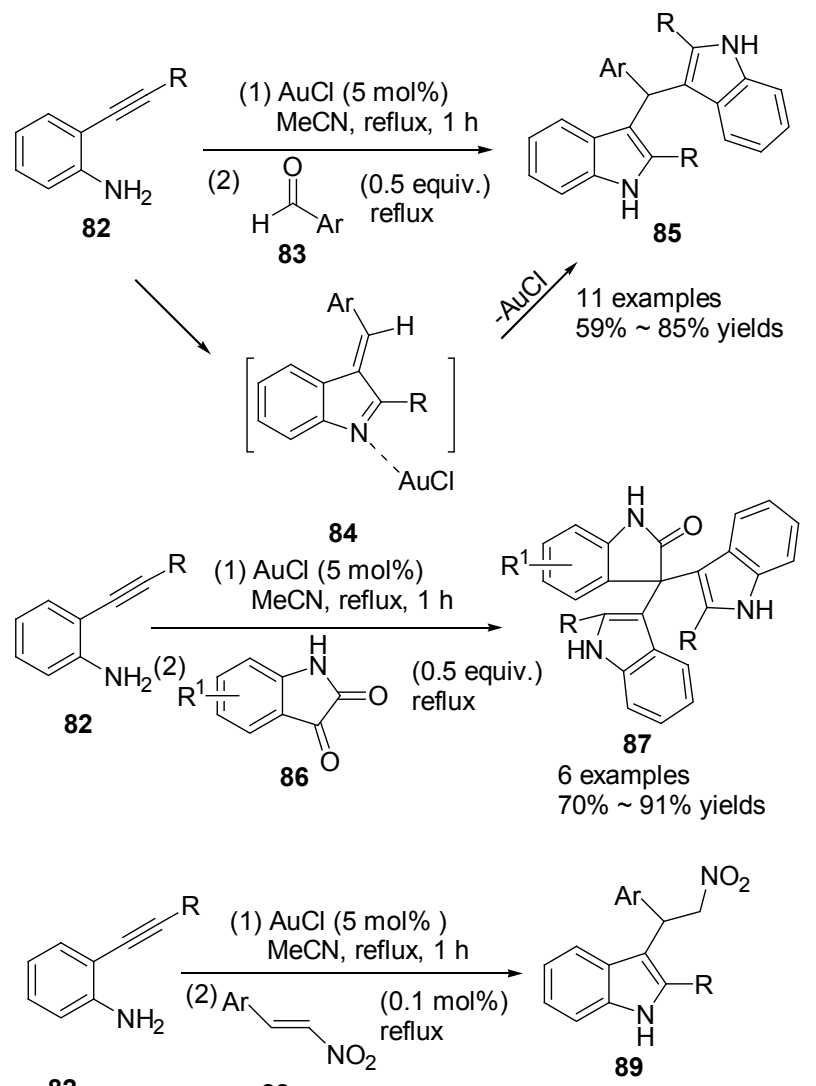

10 examples $63 \% \sim 93 \%$ yields

\section{Scheme 14}

\section{4 银催化的多米诺吲哚合成}

2010 年, Chang 等 ${ }^{[58]}$ 报道了一例银催化合成 2,3-二 取代吲哚的多米诺反应(Eq. 4). 反应以炔基亚胺酯 90 和 具有活泼亚甲基的化合物 91 为底物, 经过银催化的缩 合反应、环异构化反应和烯基转移的多米诺过程, 结果 出现了新奇的 1,3-烯基转移现象, 生成产物不是 1-烯基 取代吲哚, 而是 3-烯基取代的吲哚 92, 产率可达 83\%. 该反应操作简单、原料易得, 并且能够原位进行具有区 域选择性的烯烃转移, 所以可以作为理想的合成 3-烯基 吲哚的方法.

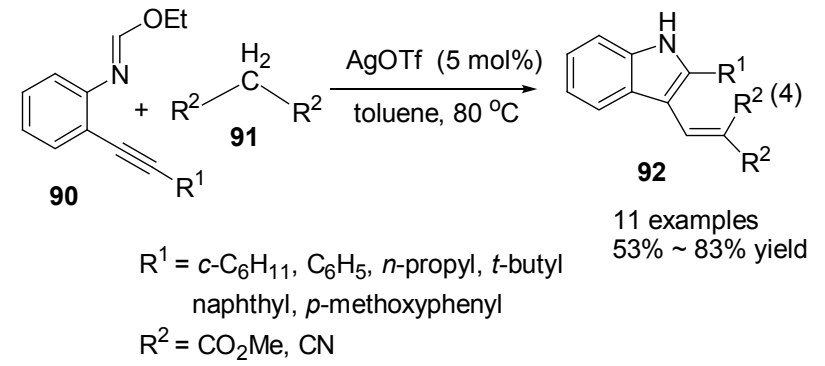

\section{5 铑催化的多米诺吲哚合成}

2008 年, Fagnou 课题组 ${ }^{[59]}$ 提出了一种以铑为催化 剂, 通过乙酰苯胺 93 和非末端炔烃 94 的氧化偶联和分 子内环化反应，一步合成多取代吲哚衍生物 95, 产率可 达 $83 \%$ (Eq. 5). 该反应简单高效，原料易得，底物适用 性较好, 为新型金属催化合成吲哚衍生物提供了一种新 方法.

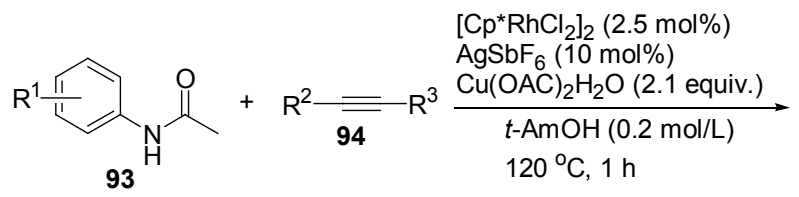

$$
\begin{aligned}
& \text { Ac } 15 \text { examples }
\end{aligned}
$$

2010 年, Lautens 小组 ${ }^{[60]}$ 将铑催化剂应用到以邻炔 基苯胺合成吲哚的反应中，报道一种合成 2-取代吲哚的 新型多米诺反应(Scheme 15). 该反应以邻炔基苯胺 95 为底物，经过中间体 97 形成瞬时的杂环铑中间体 98, 继而生成多取代吲哚化合物 99. 烷基和苯基取代的炔 基苯胺，收率可达 93\%和 91\%，但当 $\mathrm{N}$ 位未被保护或 者是芐基苯胺时, 反应不能进行. 所以, 该反应适用范 围不广，具有一定的局限性.

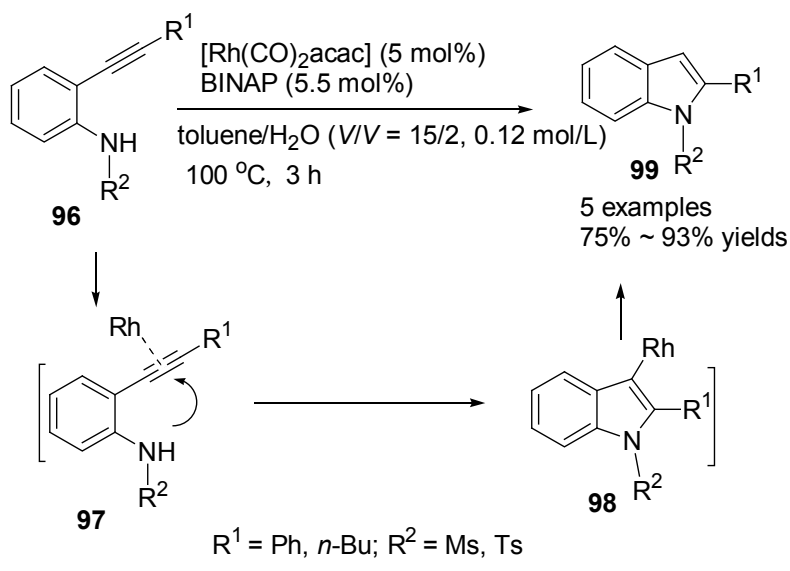




\section{6 双金属协同催化的多米诺吲哚合成}

Muller 等 ${ }^{[61]}$ 在 2010 年报道了一种 $\mathrm{Pd}-\mathrm{Cu}$ 协同催化 的多米诺反应来合成 2,4-二芳基吡喃并 [2,3- $b$ ]吲哚的反 应(Scheme 16). 该反应以邻碘代炔酰苯胺(100)和芳基 乙炔(101)为原料, 先氧化加成生成中间体 102 , 继而发 生分子内炔烃的插入生成中间体 103 , 然后与铜结合的 炔烃再和中间体 103 发生偶联反应生成中间体 104, 最 后通过环异构化过程生成 2,4-二芳基吡喃并[2,3- $b$ ] 吲哚 产物 105, 产率可达 54\%. 产物具有独特的光物理性质, 通过质子化、甲基化或者与金属离子络合后能表现出较 高的苂光灵敏度, 能充当具有金属选择性的新型冷光传 感物质.<smiles>[R]C#CC(=O)Nc1ccccc1I</smiles>

$\mathrm{PdCl}_{2}\left(\mathrm{PPh}_{3}\right)_{2}(5 \mathrm{~mol} \%)$
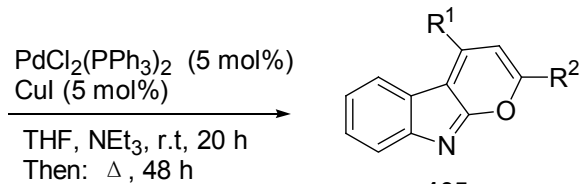

105

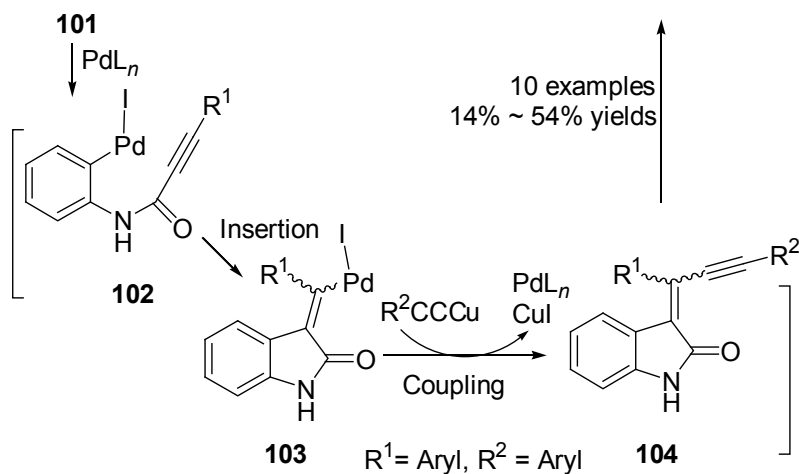

\section{Scheme 16}

此外, 2012 年, Sridhar 小组 ${ }^{[62]}$ 报道了一种在金和银 协同催化作用下，以 2-(4-氨基丁-1-炔-1-基)苯胺(106)与 醛类 107 为底物, 通过多米诺反应合成多环吲哚衍生物 的反应(Scheme 17). 该反应首先是在金催化下, 底物 106 的炔基与 $\mathrm{Au}(\mathrm{I})$ 阳离子形成 $\pi$ 配位的中间体 108, 随 后分子内氨基的亲核进攻生成中间体 109, 进一步脱金 属生成吲哚中间体 110. 之后, 被活化的醛类 107 与中 间体 110 发生亲核加成反应生成中间体 111, 最后再通 过 Pictet-Spengler 反应, 生成对应的 1-芳基- $N$-对甲苯磺 酰基-2,3,4,5-四氢吡啶并 [4,3- $b]$ 吲哚(112), 产率可达 $80 \%$. 然而, 单独使用金催化剂并不能使反应很好的进 行, $\operatorname{Ag}(\mathrm{I})$ 盐在此催化循环中起到诱导 $\mathrm{Au}(\mathrm{I})$ 的生成作用, 从而提高反应速率. 这也是首次通过串联的分子内环化 过程和 Pictet-Spengler 反应来合成此类化合物的方法. 该方法能够在相对温和、中性的条件下形成 $\mathrm{C}-\mathrm{C}$ 键,
适用范围广泛，具有很好的取代基的兼容性.

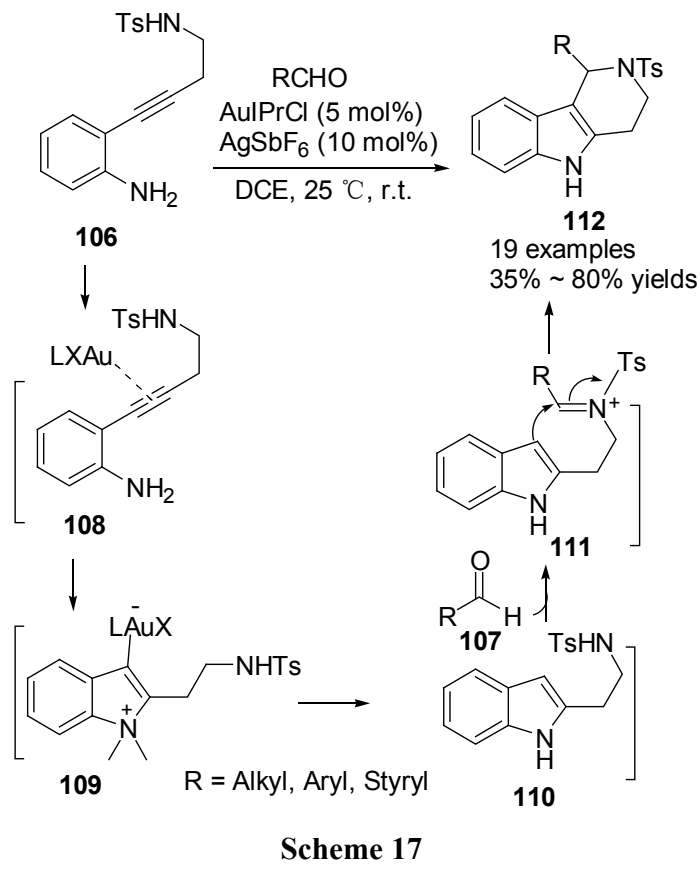

\section{7 无过渡金属催化的多米诺吲哚合成}

如今，金属催化剂会对产物造成一定程度的金属残 留, 并且对金属残留的后处理操作也相对比较繁琐. 因 此，对无金属催化的多米诺反应的研究也成为最近几年 来多米诺反应发展的一个方向. 本文在此也对无金属催 化的多米诺吲哚合成反应做一点介绍，以便与前述各类 金属催化的多米诺吲哚合成反应进行对比. 由于缺少催 化剂, 此类多米诺反应的启动就较难引发, 因此, 使用 特殊的反应条件来启动多米诺反应就成为该领域研究 的重点.

早在 2008 年, Wang 等 ${ }^{[63]}$ 利用与重氮基相连的碳带 有部分的负电荷，具有一定的亲核能力，以 $N$-芳基酰胺 (113) 和重氮基乙酸乙酯(114)为底物, 在三氟甲磺酸酤 $\left(\mathrm{Tf}_{2} \mathrm{O}\right), 2-\mathrm{ClPy}$ 和 2,6- $\mathrm{Cl}_{2} \mathrm{Py}$ 的共同作用下发生多米诺反 应生成 2,3-二取代的吲哚产物, 产率高达 82\% (Scheme 18). 该反应是在 3 种物质共同参与下进行的, 2-ClPy 与 酰胺 113 加成生成活化的亲电中间体 115 , 继而与 2,6- $\mathrm{Cl}_{2} \mathrm{Py}$ 进行可逆交换形成更加活泼的亲电体 116, 由 化合物 114 转化而来的重氮阴离子对其进攻生成重氮 中间体 117 , 并释放 2,6- $\mathrm{Cl}_{2} \mathrm{Py} \cdot \mathrm{TfOH}$, 随后再发生分子 内的亲电取代反应生成中间体 118 , 并伴随着 $\mathrm{N}_{2}$ 和 $\mathrm{TfOH}$ 的放出而生成中间体 119, 最后进行异构化形成 吲哚产物 120. 研究表明, 2,6- $\mathrm{Cl}_{2} \mathrm{Py}$ 对多米诺反应的发 生起着决定性的作用. 该反应能在低温下进行, 并且反 应速度较快, 为合成具有生物活性的吲哚衍生物提供了 一种简单有效的方法.

另外, 由于微波加热能提高反应转化率和选择性, 

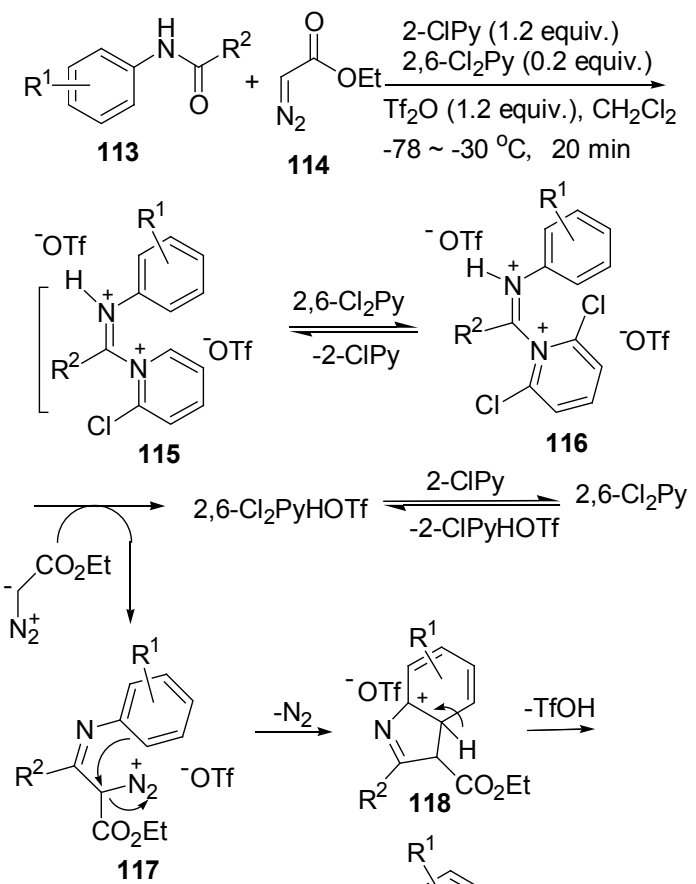

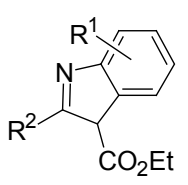

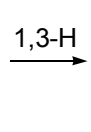

119

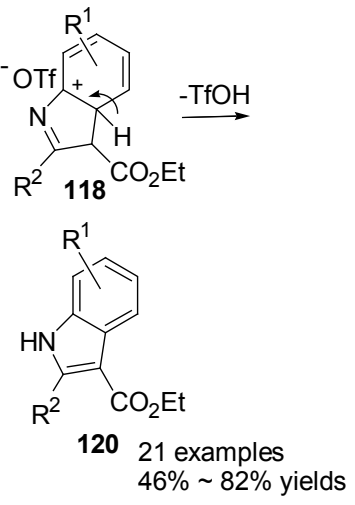

Scheme 18

还具有节能环保等优点, 现在已经成为实现绿色化学的 手段之一. 2012 年, $\mathrm{Li}$ 等 ${ }^{[64]}$ 以微波作为加热条件, 报道 了一种用于合成四环的苑并 $[1,2-b]$ 吲哚衍生物的三组分 多米诺反应(Scheme 19). 在微波条件下, 该反应开始于 2,2-二羟基狮-1,3-二酮(121)与烯胺酮 122 的亲核取代反 应, 生成中间体 124, 继而发生分子内环化生成中间体 125. 然后, 在乙酸䣶 123 作用下脱水生成中间体 $\mathbf{1 2 6}$, 继而碳正离子异构化转化为中间体 $\mathbf{1 2 7}$, 然后发生甲基 转移现象而转化为中间体 $\mathbf{1 2 8}$, 再发生去质子化作用而 生成中间体 129, 最后在化合物 $\mathbf{1 2 3}$ 作用下发生芳构化/ 酯化反应而生成最终产物 130, 产率高达 87\% (Scheme 19). 另外, 该反应具有操作简单(一锅煮)、条件温和(微 波条件)、无需催化剂和添加其他试剂, 反应时间短 (15 32 min), 取代基的范围广泛和唯一的副产物是水 等优点, 还具有很高的区域选择性和立体选择性, 为合 成此类多环取代的吲哚化合物提供了一种行之有效的 新方法.

\section{2 结论与展望}

基于多米诺反应的吲槑合成方法，因其简便高效、 原子经济性等优点而得到越来越多的关注与研究. 近年 来, 在这方面报道的文献层出不穷, 种类繁多, 综合起

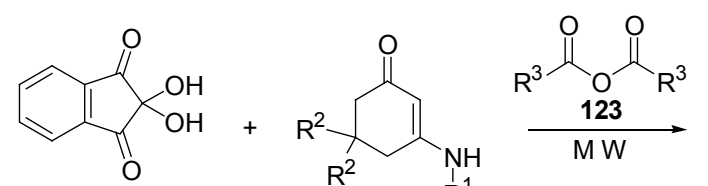
$122 R^{1}$

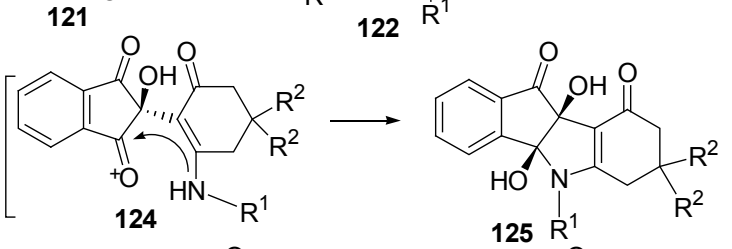
$125 R^{1}$

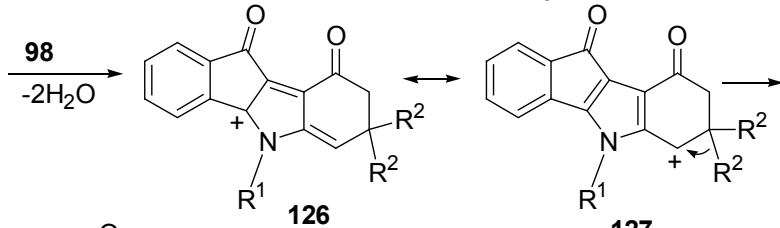

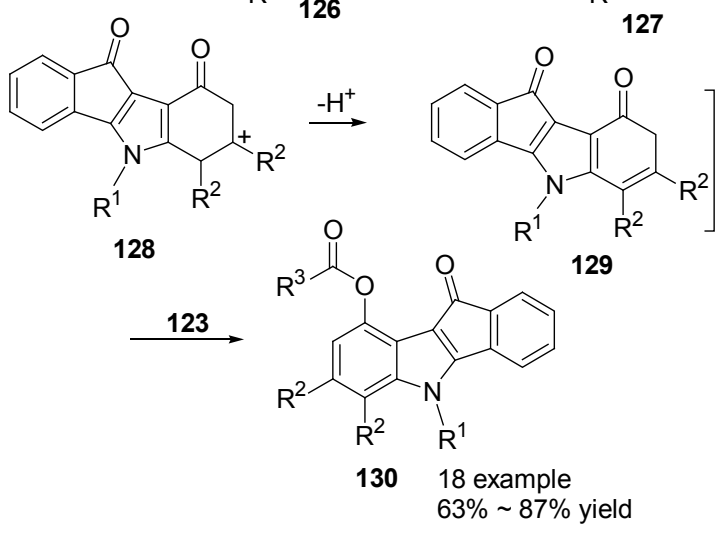

Scheme 19

来文献的聚焦点在于，(1)基于多米诺反应构筑吲哚的方 法学研究. 例如, 寻找合适的催化剂和反应条件将已知 的偶联、环化、烃化等反应结合起来，从简单易得的原 料开始, 无需合成前体化合物, 以多米诺过程直接得到 多取代的吲哚化合物; (2)基于多米诺反应构建具有广泛 用途的吲哚母核，以此快速高效地合成一系列在医药或 者材料上具有重要价值的分子，例如药物中间体、苂光 材料等; (3)将多米诺吲哚合成反应应用到含吲哚环的天 然产物的全合成中，对一些结构已知、高价值、传统方 法难以获得的天然产物的合成方法进行简化与改进.

随着绿色化学的发展要求和提高原子利用率的需 要, 在吲哚的多米诺合成方法中, 底物更加廉价易得、 反应条件更加简便温和、催化剂更加环保高效、产率进 一步提高、选择性合成进一步优化等，仍是这一领域需 要关注和解决的问题. 另外, 对吲哚及其衍生物的多米 诺合成反应机理的研究有待深入. 因此, 为了实现将简 便高效的多米诺反应应用到更多化合合成领域中，对其 机理的深入研究是非常重要, 也是不可缺少的.

\section{References}

[1] Sundberg, R. J. Indoles, Academic Press, London, 1996, pp. 12 15. 
[2] Joule, J. A.; Thomas, E. J. Sci. Synth. 2001, 361.

[3] Horton, D. A.; Bourne, G. T.; Smythe, M. L. Chem. Rev. 2003, 103, 893.

[4] Fischer, E.; Jourdan, F. Ber 1883, 16, 2241.

[5] Mori, M.; Chiba, K.; Ban, Y. Tetrahedron Lett. 1977, 1, 1037.

[6] Hemetsberger, H.; Knittel, D.; Weidmann, H. Monatsh. Chem. 1970, 101, 161

[7] Aold, K.; Peat, A. J.; Buchwald, S. L. J. Am. Chem. Soc. 1998, 120, 3068.

[8] Sundberg, R. J.; Lin, L. S.; Blackburn, D. E. J. Heterocycl. Chem. 1969, 6, 441 .

[9] Ketcha, D. M.; Wilson, L. J.; Portlock, D. E. Tetrahedron Lett. 2000, 41, 6253.

[10] Larock, R. C.; Yum, E. K.; Refvik, M. D. J. Org. Chem. 1998, 63, 7652.

[11] Li, S.; Han, J.; L, A. Acta Chim. Sinica 2013, 71, 295 (in Chinese). (李森, 韩静, 李昂, 化学学报, 2013, 71, 295.)

[12] (a) Zuo, Z. Z.; Xie, W. Q.; Ma, D. W. J. Am. Chem. Soc. 2010, 132, 13226.

(b) Zuo, Z. W.; Ma, D. W. Angew. Chem., Int. Ed. 2011, 50, 12008. (c) Zi, W. W.; Xie, W. Q.; Ma, D. W. J. Am. Chem. Soc. 2012, 134, 9126.

[13] Zhang, D.; Qin, Y. Acta Chim. Sinica 2013, 71, 147 (in Chinese). (张丹, 秦勇, 化学学报, 2013, 71, 147.)

[14] Qiu, H.; Zhang, D.; Liu, S. Y.; Qiu, L.; Zhou, J.; Qian, Y.; Zhai, C. W.; Hu, W. H. Acta Chim. Sinica 2012, 70, 2484 (in Chinese). (邱晃, 张丹, 刘顺英, 邱林, 周俊, 钱宇, 翟昌伟, 胡文浩, 化 学学报, 2012, 70, 2484.)

[15] Tietze, L. F. Chem. Rev. 1996, 96(1), 115.

[16] Tietze, L. F.; Brasche, G.; Gericke, K. M. Dmino Reactions in Organic Synthesis, Weinheim, Wiley-VCH, 2006, pp. 25 30.

[17] Wender, P. A.; Miller, B. L. Nature 2009, 460(7252), 197.

[18] Battistuzzi, G.; Cacchi, S.; Fabrizi, G. Eur. J. Org. Chem. 2002, 16, 2671.

[19] Barluenga, J.; Jimenez-Aquino, A.; Valdes, C.; Aznar, F. Angew. Chem., Int. Ed. 2007, 46, 1529.

[20] Barluenga, J.; Jimenez-Aquino, A.; Aznar, F.; Valdes, C. J. Am. Chem. Soc. 2009, 131, 4031.

[21] Jensen, T.; Pedersen, H., Bang-Andersen, B.; Madsen, R.; Jørgensen, M. Angew. Chem., Int. Ed. 2008, 47, 888.

[22] Wurtz, S.; Rakshit, S.; Neumann, J.; Droge, T.; Glorius, F. Angew. Chem., Int. Ed. 2008, 47, 7230.

[23] Shi, Z. Z.; Zhang, C.; Li, S.; Pan, D. L.; Ding, S. T.; Cui, Y. X.; Jiao, N. Angew. Chem., Int. Ed. 2009, 48, 4572.

[24] Romagnoli, R.; Baraldi, P. G.; Sarkar, T.; Carrion, M. D.; Cara, C. L.; Preti, D.; Tabrizi, M. A.; Tolomeo, M.; Grimaudo, S.; Zonta, N.; Balzarini, J.; Brancale, A.; Hsieh, H.-P.; Hamel, E. J. Med. Chem. 2008, 51, 1464 .

[25] Mahboobi, S.; Pongratz, H.; Hufsky, H.; Hockemeyer, J.; Frieser, M.; Lyssenko, A.; Paper, D. H.; Burgermeister, J.; Bohmer, F.-D.; Fiebig, H.-H.; Burger, A. M.; Baasner, S.; Beckers, T. J. Med. Chem. 2001, 44, 4535.

[26] Arthuis, M.; Pontikis, R.; Florent, C. Org. Lett. 2009, 11, 4608.

[27] Mao, H.; Wan, J. P.; Pan, Y. J.; Sun, C. R. Tetrahedron Lett. 2010, 51,1844 .

[28] Beletskaya, I. P.; Cheprakov, A. V. Chem. Rev. 2000, 100, 3009.

[29] Catellani, M.; Motti, E.; Della, C. N. Acc. Chem. Res. 2008, 41, 1512.
[30] Candito, D. A.; Lautens, M. Org. Lett. 2010, 12, 3312.

[31] Faccini, F.; Motti, E.; Catellani, M. J. Am. Chem. Soc. 2004, 126, 78.

[32] Hassner, A.; Bunnell, C. A.; Haltiwanger, K. J. J. Org. Chem. 1978, $43,57$.

[33] Shen, J. H.; Cheng, G. L.; Cui, X. L. Prog. Chem. 2012, 24, 1324 (in Chinese). (沈金海, 程国林, 崔秀灵, 化学进展, 2012, 24, 1324.)

[34] Wang, Y.; Wang, H.; Peng, J.; Zhu, Q. Org. Lett. 2011, 13, 4604.

[35] Nanjo, T.; Tsukano, C.; Takemoto, Y. Org. Lett. 2012, 14, 4270.

[36] Piou, T.; Neuville, L.; Zhu, J. P. Tetrahedron 2013, 69, 4415.

[37] Fernandez, L. S.; Buchanan, M. S.; Carroll, A. R.; Feng, Y. J.; Quinn, R. J.; Avery, V. M. Org. Lett. 2009, 11, 329.

[38] Yokoyama, Y.; Matsumoto, T.; Murakami, Y. J. Org. Chem. 1995, $60,1486$.

[39] Tan, B.; Torres, G. H.; Barbas, C. F. J. Am. Chem. Soc. 2011, 133, 12354.

[40] Love, B. E.; Raje, P. S. Synlett 1995, 1061.

[41] Zhang, Y. H.; Liu, S.; Yu, W. W.; Hu, M.; Zhang, G. L.; Yu, Y. P. Tetrahedron 2013, 69, 2070.

[42] Xu, C.; Murugan, V. K.; Pullarkat, S. A. Org. Biomol. Chem. 2012, 10, 3875 .

[43] Tsuji, J.; Takahashi, H.; Morikawa, M. Tetrahedron Lett. 1965, 6(49), 4387.

[44] Bandini, M.; Melloni. A.; Ronchi, A. U. Angew. Chem., Int. Ed. 2004, 43, 550 .

[45] Evano, G.; Blanchard, N.; Toumi, M. Chem. Rev. 2008, 108, 3054.

[46] Li, J. H.; Tang, B. X.; Tao, L. M.; Xie, Y. X.; Liang, Y.; Zhang, M. B. J. Org. Chem. 2006, 71, 7488 .

[47] Altman, R. A.; Buchwald, S. L. Org. Lett. 2006, 8, 2779.

[48] Chen, Y.; Xie, X. A.; Ma, D. W. J. Org. Chem. 2007, 72, 9329.

[49] Ali, M. A.; Punniyamurthy, T. Synlett 2011, 623.

[50] Xia, Z. M.; Wang, K.; Zheng, J. N.; Ma, Z. Y.; Jiang, Z. J.; Wang, X. X.; Lv, X. Org. Biomol. Chem. 2012, 10, 1602.

[51] Ma, S.; Cai, Q. Acc. Chem. Res. 2008, 41, 1451.

[52] Oda, Y.; Hirano, K.; Satoh, T.; Miura, M. Org. Lett. 2012, 14, 664.

[53] Salzner, U.; Lagowski, J. B.; Pickup, P. G.; Poirier, R. A. Synth. Met. 1998, 96, 177.

[54] Park, J.; Park, E.; Kim, A.; Park, S. A.; Lee, Y.; Chi, K. W.; Jung, Y. H.; Kim, I. S. J. Org. Chem. 2011, 76, 2214.

[55] Ponpandian, T.; Muthusubramanian, S. Tetrahedron Lett. 2012, 53, 4248.

[56] Ambrogio, I.; Arcadi, A.; Cacchi, S.; Fabrizi, G.; Marinelli, F. Synlett 2007, 1775.

[57] Praveen, C.; Karthikeyan, K.; Perumal, P. T. Tetrahedron 2009, 65, 9244.

[58] Chang, H. O.; Karmakar, S.; Park, H.; Ahn, Y.; Kim, J. W. J. Am. Chem. Soc. 2010, 132, 1792.

[59] Stuart, D. R.; Bertrand-Laperle, M.; Burgess, K. M. N.; Fagnou, K. J. Am. Chem. Soc. 2008, 130, 16474.

[60] Boyer, A.; Isono, N.; Lackner, S.; Lautens, M. Tetrahedron 2010, $66,6468$.

[61] Schonhaber, J.; Frank, W.; Muller, T. J. J. Org. Lett. 2010, 12, 4122.

[62] Reddy, B. V. S.; Swain, M.; Reddy, S. M.; Yadav, J. S.; Sridhar, B. J. Org. Chem. 2012, 77, 11355.

[63] Cui, S. L.; Wang, J.; Wang, Y. G. J. Am. Chem. Soc. 2008, 130, 13526.

[64] Jiang, B.; Li, Q. Y.; Tu, S. J.; Li, G. G. Org. Lett. 2012, 14, 5210.

(Qin, X.) 